\title{
Del deseo universal de paz, del comercio como productor de la misma, y del pensamiento de Hume sobre el refinamiento en las artes
}

\section{The universal desire for peace, trade as a producer of peace, and the thinking of Hume on the refinement in the arts}

\author{
Gerardo López Sastre ${ }^{1}$ \\ Universidad de Castilla-La Mancha (España)
}

Recibido: 08-06-14

Aprobado: 01-07-14

\section{Resumen}

Comenzando con un antiguo filósofo chino, Mozi, y analizando el pensamiento de David Hume, vemos dos formas diferentes de abordar el problema de la consecución de la paz: apelando directamente a la razón o estudiando el curso de la Historia, en donde se manifiestan fuerzas -como el comercio y su influencia en el ámbito de la moral- que como un efecto social no buscado directamente acaban produciéndola.

Palabras-clave: Hume, guerra, paz, comercio, artes.

\begin{abstract}
We start studying an ancient Chinese philosopher, Mozi, and later we discuss the thought of David Hume. In this way we see two different methods of addressing the problem of achieving peace: appealing directly to reason or

\footnotetext{
${ }^{1}$ (Gerardo.Lopez@uclm.es). Gerardo López Sastre se ha ocupado fundamentalmente del pensamiento moderno en el mundo anglosajón. Entre sus publicaciones más recientes se encuentran una traducción de Tres ensayos sobre la religión de J. S. Mill (Trotta, 2014), el capítulo titulado "David Hume on Religious Tolerance", (en Paradoxes of Religious Toleration in Early Modern Political Thought, Lexington Books, 2012) y "The Dialogues Concerning Natural Religion as Sociology of Knowledge" (en Hume et la religion: nouvelles perspectives, nouveaux enjeux, Georg Olms, 2013).
} 
studying the course of history, where forces such as trade and its impact on the field of morality produce peace as an unintended social effect.

Key-words: Hume, war, peace, commerce, arts.

\section{Un ejemplo del carácter global del deseo de paz}

Seguramente protestas en contra de las guerras y deseos de paz ha habido siempre. Donde había enfrentamientos cabe esperar que hubiera personas que se opusieran a los mismos y a los males sociales que acarreaban. Es más, la reflexión sobre el origen de los conflictos bélicos y sobre cómo podrían evitarse no es patrimonio exclusivo del pensamiento occidental. Baste pensar, por poner dos ejemplos tomados del mundo chino antiguo, en el caso del mohismo y del taoísmo. De hecho, por centrarnos en el mohismo, en esta filosofía se describió con un gran realismo, muy lejos de cualquier exaltación épica, el carácter terrible de las campañas militares, al menos desde el punto de vista de los campesinos reclutados a la fuerza: "reclutar tropas no es conveniente en invierno por los grandes fríos, en verano por los grandes calores, en primavera por impedir las labores de roturar, sembrar y plantar, en otoño por impedir la recolección de la cosecha. En cualquiera de las estaciones, les impides sus tareas y expones a innumerables gentes del pueblo a morir de hambre y frío. Numerosos los gastos inmensos que trae una guerra... Bueyes y caballos que van bien cebados y volverán flacos y muchísimos no volverán por haber sido muertos. Además, las largas caminatas, falta de víveres que no llegan a tiempo. Gentes de pueblo que mueren innumerables... Innumerable la gente que enferma y muere por los caminos, pérdidas innumerables sufridas por los batallones, innumerables batallones completamente aniquilados. ${ }^{2}$ No sólo encontramos esto; además se va a intentar dar una explicación de cómo se ha llegado a esta situación caracterizada por la presencia de desigualdades sociales extremas y de la guerra. Para Mozi el origen de las desgracias del momento está en el egoísmo, la parcialidad y la aplicación de un sorprendente doble rasero. Escribirá a este respecto: "Si alguien entra en un huerto ajeno y roba melocotones y ciruelas, todos cuantos se han enterado lo reprueban. Y, si el gobernante es informado de ello, lo castiga. ¿Por qué? Porque se ha beneficiado a sí, perjudicando al vecino. Si lo que ha robado ha sido un perro, un cerdo, una gallina o un lechoncito, su injusticia es mayor que la de haber entrado en el huerto y robado melocotones o ciruelas ¿Por qué? Porque el mal causado al prójimo ha sido más cuantioso y mayor la falta de caridad, y su

\footnotetext{
${ }^{2}$ Mo Ti, Política del amor universal. Estudio preliminar de Fernando Mateos. Traducción y notas de Carmelo Elorduy. Madrid, Ed. Tecnos, 1987, p. 67.
} 
delito más grave. Entrar en el establo de otro y llevarse un caballo, un buey, es mayor falta de caridad y justicia que la de haber robado un perro, un cerdo, una gallina o un lechoncito. ¿Cuál es la razón? El perjuicio causado es más cuantioso, la falta de caridad es más grave y el delito mayor. Al matar a un inocente, robarle sus vestidos y sus pieles, hurtarle su lanza y su espada, la injusticia cometida es mayor que la de robarle su caballo o su buey. ¿Cuál es la razón? Porque el perjuicio causado al prójimo ha sido más grave. Cuanto el daño causado al prójimo es mayor, la falta de caridad con él es más grave y el delito mayor. Los reyes que gobiernan en el mundo lo saben, y lo reprueban calificándolo de injusticia. Pero una cosa mucho mayor, el atacar a otro Estado, no lo reconocen como malo, sino que lo alaban y lo juzgan justo. ¿Se puede llamar a esto saber distinguir la justicia de la injusticia? Asesinar a uno se califica de injusticia, e indefectiblemente se castiga con la muerte. Según esto, matar a diez será crimen diez veces mayor y merecerá ser castigado con diez penas capitales. Pero no reconocen que atacar a otro Estado es malo y una injusticia mayor, sino que lo elogian y lo juzgan acción justa. En verdad, ignoran que sea una injusticia y escriben sus hazañas guerreras para las generaciones futuras. Si lo reconocieran como injusticia, ¿acaso hablarían de ellas y las escribirían para dejar memoria a las generaciones futuras? [...] ¿Se puede decir que sabe distinguir lo justo de lo injusto quien juzga por mala una cosa un poco mala y la condena, y otra inmensamente peor, cual es atacar a otro Estado, no sabe que es mala sino que la elogia calificándola de justa? De aquí vemos la gran confusión de los reyes del mundo en distinguir lo justo y lo injusto"3. Frente a esta situación, para Mozi la solución a las guerras estaba clara: quienes se aplicaron a establecer el orden y la paz en el mundo, lograron su propósito porque se dieron, indefectiblemente, a conocer antes el origen de los disturbios. Si se ignora el origen del desorden, no se podrá remediarlo. Lo mismo que un médico, para atacar una enfermedad, precisa conocer su origen. "Examinando el origen de los disturbios hallaron que la causa era que no había mutuo amor entre los hombres. [...] Todo viene de no amarse mutuamente. Lo mismo que los peores bandidos del mundo. Un bandido ama su casa y no ama la del extraño y roba la casa del extraño en beneficio de la propia. El malhechor o el ladrón aman su propia persona y no aman la de los demás y roban o causan daños a los otros para beneficiarse a sí mismos. [...] Los señores feudales aman sus propios estados y no aman los estados de los demás y atacan los estados de los vecinos en beneficio de sus propios estados. Si se lograra que todos en el mundo se amaran mutuamente,

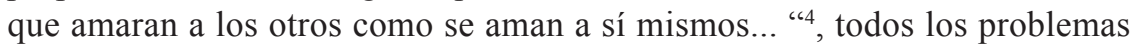
sociales desaparecerían, y reinarían el orden y la paz.

${ }^{3}$ Política del amor universal, pp. 65-66. Hemos modificado muy ligeramente la traducción.

${ }^{4}$ Politica del amor universal, p. 51-52. 
La respuesta es tan simple como, podemos pensar, ingenua. Dicho de otra forma, impracticable. Algo de lo que ya nos habría advertido Freud en El malestar en la cultura hablando del mandamiento "Amarás al prójimo como a ti mismo"s. Pero Mozi contesta a un supuesto oponente que si fuera impracticable aun él mismo la desaprobaría (y esto es, desde luego, lo que un utilitarista -como era Mozi- debe hacer), y se apresura a poner dos ejemplos destinados a disipar nuestras dudas sobre la inaplicabilidad del principio.

1. Imaginemos que estamos en una amplia llanura desértica, que gentes armadas de corazas y yelmos (entre las que nos encontramos nosotros mismos) van a entrar en batalla. La contingencia de la vida y la muerte es desconocida. No sabemos si sobreviviremos al choque de los ejércitos. ¿A quién confiaríamos el cuidado de nuestra familia, de nuestros hijos o de nuestros ancianos padres? ¿A alguien que considera que el amor universal es una quimera irrealizable o a quien declara que es posible lograrlo y afirma que intenta ponerlo en práctica?

2. "Viene un año de peste. Entre los millares de gentes del pueblo son muchos los que, agotados de fatiga y hambre, se revuelcan moribundos a la vera de acequias y canales", y hay otros muchos que no saben a dónde ir. ¿Hacia dónde deberían encaminar sus pasos? ¿Hacia el Estado de un soberano que afirma el principio del amor universal e intenta realizarlo, o al de quien declara rotundamente que es inviable? ${ }^{6}$ Luego la superioridad teórica del principio, y que es capaz de ponerse en práctica, la reconocen en estos ejemplos, siempre según Mozi, incluso los que habían declarado primero su inviabilidad?

Además, y con vistas a hacer más aceptable la propuesta de Mozi, hay que mencionar (o aclarar) que no estamos hablando de un sentimiento. No se trata de amar efectivamente a los otros, sino de comportarnos como si los amásemos. $Y$ este comportamiento podría ponerse en práctica en cuanto comprendiésemos que "hacerse bien recíprocamente reporta bienes innumerables": la paz, el orden y una cooperación que a todos beneficia ${ }^{8}$.

Pero en todo caso, visto el transcurso de la Historia tanto en China como en el resto del mundo, no parece que haya que insistir mucho sobre el carácter

\footnotetext{
${ }^{5}$ Véase Sigmund Freud, El malestar en la cultura y otros ensayos. Traducción de Ramón Rey. Madrid, Alianza Ed., 1975, 3 ed., p. 85.

${ }^{6}$ Véase Política del amor universal, pp. 57-58.

${ }^{7}$ A todo el razonamiento anterior se añade la creencia en una divinidad que lo ve todo "muy segura y claramente", Política del amor universal, p. 98. Quienes se conformen a su voluntad (que ama la vida y aborrece la muerte) serán premiados. Los que se oponen a la misma y se odian mutuamente, haciéndose daño unos a otros, serán castigados, véase Política del amor universal, p. 99.

${ }^{8}$ Anne Cheng escribe sobre este tema: "El <<amor universal $>>$ de Mozi no es, pues, el $<<$ amor hacia el prójimo $>>$ del que hablaba Confucio. No tiene que ver con la emoción o el sentimiento, sino más bien con una preocupación imparcial y razonada por todos los hombres". Anne Cheng: Historia del pensamiento chino. Traducción de Anne-Hélêne Suarez. Bellaterra, Barcelona, 2002, p. 91. Un interesantísimo análisis de los términos chinos que Mozi emplea y cómo deben entenderse, se encuentra en el Estudio preliminar de Fernando Mateos a la traducción por la que estamos citando la obra. Véanse las pp. XXXIV-XXXVI.
} 
exageradamente optimista del pensamiento de nuestro autor. Es verdad que cuando los reyes piden a la gente que se mate por ellos, la gente va a la guerra y muere, luego aparentemente si los gobernantes pidieran a la gente que se amara mutuamente (lo que no parece que implique tanto riesgo para nuestra vida como participar en una batalla) sería fácil que obedecieran. Pero, como tuvo ocasión de comprobar Pedro el Grande, le era prácticamente imposible obligar a sus súbditos a que se cortasen la barba, y sin embargo no le fue nada difícil hacerles marchar a la batalla para despedazar a unos vecinos que no les habían hecho daño alguno ${ }^{9}$. Luego no puede afirmarse sin más que el hombre sea racional, un ser atento al principio de utilidad. Nuestra naturaleza psicológica es bastante más compleja, aunque esto parece más un motivo de lamentación (al menos en el ámbito de la política) que otra cosa; y esto es excepcionalmente importante, porque de acuerdo con la interpretación que voy a proponer de al menos una parte importante del pensamiento ilustrado, este no ha caído en lo que podemos llamar "el error intelectualista" de Mozi (pensar que basta con que sepamos lo que nos conviene a largo plazo para que lo hagamos), y por lo tanto es inmune a la crítica de anti-ilustrados convencidos como Joseph de Maistre, quien, en el resumen de sus tesis que presenta Stephen Holmes, pensaba que: "El irresistible atractivo de la guerra domina nuestra vida aun cuando sea absolutamente contrario a la razón y al instinto de autoconservación (que airean los liberales). Es absurdo pretender, como característicamente hacen los pensadores de la Ilustración, que la guerra le fue impuesta al pueblo desde arriba... Por el contrario, la guerra es compulsiva; es a la vez completamente inhumana y completamente humana. Es, por consiguiente, el ejemplo perfecto de lo irresoluble del enigma de la vida. La guerra resiste todo esfuerzo racionalista de iluminar las tinieblas... El individuo no es un agente racional capaz de asignar medios eficaces a la consecución de fines claramente formulados. Es un juguete a merced de fuerzas superiores que no puede dirigir ni comprender. La noción de enemistad violenta, la idea de que existe alguien a quien debemos enfrentarnos y matar es perfectamente innata, instintiva, prerracional" 10 .

\section{La confianza de la Ilustración en el comercio como productor de paz}

Aclarado ya (aclaración que nos parecía muy necesaria) que los ideales de paz y la reflexión sobre los orígenes de las guerras no son algo exclusivo de la cultura europea, lo que sí cabe preguntarse es si ha habido alguna característica propia del pensamiento occidental en este ámbito de reflexión. Pues bien, nosotros

\footnotetext{
${ }^{9}$ Citado por Stephen Holmes, Anatomía del antiliberalismo. Trad. de Gonzalo del Puerto. Madrid, Alianza Ed., 1999, pp. 51-52.

${ }_{10}$ Loc. Cit.
} 
vamos a insistir en una tesis específica que se desarrolló en el pensamiento moderno, tesis que se encuentra en diversos autores ilustrados, pero que está muy bien ejemplificada en varias obras del filósofo escocés David Hume. La tesis general la expuso admirablemente Albert Hirschman en su obra ya clásica, Las pasiones y los intereses. Argumentos politicos en favor del capitalismo antes de su triunfo ${ }^{11}$. Allí, la historia que cuenta Hirschman tiene que ver con el hecho de que en el Renacimiento surgió la sensación, convertida en convicción firme más tarde, de que no se podía confiar en una filosofía moralizadora y en las recomendaciones religiosas para controlar o restringir las pasiones destructivas de los hombres ${ }^{12}$. Pues bien, ¿no podrían los intereses materiales, que por ejemplo podían satisfacerse a través del comercio, controlar a esas pasiones destructivas? Hirschman cita a este respecto la conocida afirmación del Dr. Johnson de que "Hay pocas empresas en que un hombre pueda emplearse más inocentemente que en la obtención del dinero" (en Vida de Samuel Johnson, de James Boswell, con fecha 27 de marzo de 1775) ${ }^{13}$. La idea de que la persecución del dinero pudiera ser una actividad inocente no tenía, desde luego, nada de clásica. La actitud cristiana hacia el comercio lo había considerado por el contrario como una actividad poco menos que diabólica, prestar con interés era el pecado de la usura, y como había afirmado san Jerónimo "El comerciante pocas veces o jamás puede complacer a Dios"14. Por el contrario, ahora buscar enriquecerse era visto como una actividad que no planteaba objeciones morales, admitiendo -claro está- que esa actividad muchas veces se producía a través del comercio. Es más, a esta actividad o a su resultado se la denominaba "douce". Montesquieu escribirá: "es casi una regla general que allí donde hay costumbres apacibles [moeurs douces] existe el comercio, y que allí donde hay comercio hay costumbres apacibles", o más adelante: "El comercio... pule y hace apacibles [adoucit] los usos bárbaros"15. El historiador escocés William Robertson, contemporáneo de Hume, defenderá la misma tesis: "El comercio tiende a suprimir aquellos prejuicios que mantienen las distinciones y la animosidad entre las naciones. Suaviza y pule los modales de los hombres"16. Esta es una idea fácil de encontrar un poco por todas partes en

11 Hay dos versiones españolas de este libro. La primera publicada por el Fondo de Cultura Económica, México, 1978, y con traducción de Eduardo L. Suárez. Y la segunda con Prólogo de Amartya Sen y Epílogo de Jeremy Adelman. Traducción de Joan Solé. Madrid, Capitán Swing Libros, 2014. Nosotros citaremos por esta última.

12 Véase Las pasiones y los intereses, p. 39.

13 Véase Las pasiones y los intereses, p. 79. La versión del siglo XX de esta afirmación sería la conocida opinión de Keynes de que "es mejor que un hombre tiranice su cuenta bancaria que a sus conciudadanos". Se esperaba que si uno se centraba en lo primero, estaría tan ocupado o tan entretenido que no tendría la tentación de incurrir en lo segunda posibilidad.

14 Véase Steven Pinker, Los ángeles que llevamos dentro. El declive de la violencia y sus implicaciones. Traducción de Joan Soler Chic. Ed. Paidós, Barcelona, 2012, p. 121.

15 Véase Las pasiones y los intereses, p. 82.

16 William Robertson en su View of the progress of society in Europe, que es el prefacio a su History 
el pensamiento ilustrado. Así, por ejemplo, Voltaire escribe que "la Razón viaja a cortas jornadas, de norte a sur, con sus dos amigas íntimas, la Experiencia y la Tolerancia. La acompañan la Agricultura y el Comercio"17.

¿Cómo es que el comercio podía producir resultados tan beneficiosos? ¿Cómo es que era un compañero de la misma razón y de la tolerancia? Más concretamente, ¿cómo es que podía producir la paz entre las naciones? Montesquieu era muy tajante a este respecto: "El efecto natural del comercio es la paz. Dos naciones que negocian entre sí se hacen recíprocamente dependientes: si a una le interesa comprar, a la otra le interesa vender; y ya sabemos que todas las uniones se fundamentan en necesidades mutuas." 18 Igual de tajante se mostraba Thomas Paine en su libro Derechos del hombre. Allí se habla del comercio como de un sistema pacífico, "que actúa para dar cordialidad a la humanidad, al hacer que tanto las naciones como los individuos se sean mutuamente útiles. ... Si se permitiera que el comercio actuara en la medida universal de que es capaz, extirparía la guerra del sistema y produciría una revolución en el estado incivilizado de los gobiernos. La invención del comercio surgió después de que comenzaran los gobiernos, y es el mayor avance hacia la civilización universal que jamás se ha logrado, por medios que no se deriven inmediatamente de principios morales... El comercio no es más que el tráfico entre dos individuos, multiplicado en escala numérica; y la misma norma que la naturaleza se propuso para el intercambio de dos se la propuso para el de todos. Por ese fin ha distribuido los materiales de la manufactura y del comercio en varias y distintas partes de cada nación y del mundo, y como no se pueden adquirir mediante la guerra con tanta baratura ni comodidad como por el comercio, ha hecho que este último sea el medio de extirpar a aquélla"19.

La conclusión es clara: el comercio es lo contrario de la guerra. Y si todos los que participan en una actividad comercial salen beneficiados, la reducción del comercio es mala para todos. Con una gráfica imagen que pone Paine, es lo mismo que ocurre con la sangre," no puede extraerse de una de las partes sin reducir la masa total en circulación, y todas ellas comparten la pérdida"20. $\mathrm{Y}$ es muy interesante que Thomas Paine recalque en este mismo lugar que estamos citando que nunca ha predicado la reforma teórica (diríamos con más

of the reign of the Emperor Charles $V$. Citado en la p. 82 de Las pasiones y los intereses.

17 "El hombre de los cuarenta escudos", en Voltaire, Novelas y cuentos. Introducción, traducción y notas de Carlos Pujol. Barcelona, Ed. Planeta, 1982, p. 373. Aunque también es verdad que Voltaire tenía sus momentos pesimistas (o realistas, según cómo queramos enjuiciarlos). Así en su Diccionario, en la entrada "Guerra", escribe: "lo peor es que la guerra es una plaga inevitable. Si prestamos atención, todos los hombres han adorado al dios Marte". Voltaire, Diccionario filosófico. Edición y prólogo de Luis Martínez Drake. Traducción de José Arean Fernández y Luis Martínez Drake. Madrid, Ed. Akal, 2007, p. 298.

${ }_{18}$ Essai politique sur le commerce, citado en la p. 101 de Las pasiones y los intereses.

19 Thomas Paine, Derechos del hombre. Traducción, introducción, cronología y notas de Fernando Santos Fontenla. Madrid, Alianza Ed., 1984, p. 223.

${ }^{20}$ Derechos del hombre, p. 224. 
propiedad, moralizante), sino que ha intentado -como en una parte importante de la Ilustración, añadiríamos nosotros- mejorar la condición de la humanidad apelando a su interés inmediato, a una utilidad personal que resulta que va a ser mutua. Se parte de la idea, ya mencionada, de que los discursos moralizantes no sirven para mejorar la naturaleza humana. El comercio, en efecto, no debe su triunfo a la actuación directa de principios morales. Su fuente es el interés propio, pero su resultado "indirecto" es la paz y el avance hacia una civilización universal. Más tarde volveremos a insistir en la importancia de esta conclusión.

Mientras tanto, permítasenos insistir en otro elemento característico del pensamiento ilustrado: la secularización. Una vez que nos convencemos de que ni la vida humana individual ni la sociedad como conjunto de personas tienen como objetivo manifestar la gloria de Dios (pues cabe dudar con fundamento tanto de su existencia como de que haya otra vida tras la muerte), es inevitable que aparezca la pregunta sobre cuál es la verdadera finalidad de una sociedad. La respuesta obvia es que hacer la vida de los hombres más fácil y placentera, ayudándoles así a alcanzar la felicidad. Dicho de otra forma, a partir de un determinado momento las sociedades europeas empiezan a preocuparse no de las almas de sus miembros, sino de sus vidas. Y para lograr que estas puedan florecer y lleguen así a ser felices, ¿qué era mejor? ¿Una alternativa en la que uno podía perder o ganar (y esto eran las guerras) o una opción en la que todos podían ganar? Esto último hemos visto que era el comercio. Se daba así esa confluencia tan característica del liberalismo del interés público (podríamos hablar también de la moral) y del privado (egoísta). Ambos coincidían en apuntar hacia el progreso de la única vida que podemos estar seguros de poseer: esta sobre la Tierra. Es también por ello que la filosofía de la Ilustración valoró el comercio como pocas veces se ha hecho en la historia del pensamiento. Nos permitía tener productos que hacían nuestra vida más confortable, proporcionaba el placer de lo novedoso, etc. Contribuía, en suma, a que disfrutáramos más de todo lo que el planeta podía ofrecernos para que nuestra existencia fuera más agradable. Es verdad que desde la perspectiva de la humanidad en su conjunto -y como vamos a ver dentro de un momento esta era la perspectiva propia de los ilustrados- cabría preguntarse qué ventajas obtuvieron los pueblos indígenas con su colonización. ¿Llegaron a ser más felices? No parece que podamos contestar afirmativamente a esta pregunta. El mismo James Cook se preguntaba con razón qué es lo que los nativos de toda la geografía de América habían ganado con el comercio que habían mantenido con los europeos ${ }^{21}$. Pero aquí hay que matizar que en su defensa del comercio los ilustrados no estaban pensando ni en el colonialismo ni mucho menos en la esclavitud, sino en la idea de personas o naciones soberanas que libremente comercian porque entienden

${ }^{21}$ Véase Dorinda Outram, Panorama de la Ilustración. Traducción de Ramón Martínez Castellote. Barcelona, Blume, 2008, p. 174.

Araucaria. Revista Iberoamericana de Filosofía, Política y Humanidades, año 16, no 32. Segundo semestre de 2014. Pp. 135-154. ISSN 1575-6823 e-ISSN 2340-2199 doi: 10.12795/araucaria.2014.i32.07 
que un determinado trato corresponde a sus intereses. En suma, una cosa era la rapiña y la explotación, y otra cosa era el comercio. Que como realidad histórica estas dos cosas se hayan dado mezcladas no excluye la necesidad de su distinción conceptual; y una vez establecida esta distinción, los ilustrados pensaban que el comercio quedaba legitimado no porque beneficiara a una de las partes, sino porque lo hacía con todos los que intervenían en tales tratos, lo que era como llamar a participar en los mismos a la humanidad en su conjunto. $\mathrm{Y}$ en ese beneficio no sólo contaba la prosperidad material que pudiera proporcionar - esto era lo más obvio y el incentivo directo-, sino también el hecho de que, aunque no lo buscara directamente, el comercio acababa promoviendo una situación de paz internacional. Y aquí siempre cabría pensar que el desarrollo del comercio parecía solucionar un problema que escapaba a la argumentación hobbesiana. En efecto, para Hobbes el fundamento último de la paz no dejaba de estar en la igualdad humana. En el hecho terrible de que hasta el más débil, valiéndose de la sorpresa o de la astucia, podía acabar con el más fuerte, y en la realidad de que todos deseamos las mismas cosas y no estamos dispuestos a renunciar a las mismas porque consideremos que los demás son más importantes que nosotros mismos. Simplemente, esto no sucede. Admitida esta igualdad, los hombres tienen un buen incentivo para elegir la paz, pues esta hará posible la cooperación y que su vida no se vea en riesgo de ser pobre o corta. Pero esto funciona en cuanto a los fundamentos de un Estado y, diríamos, "de puertas para adentro". ¿Qué ocurre, entonces, con las relaciones internacionales, con las relaciones entre Estados, donde es obvio que unos son mucho más poderosos que otros? ¿Hemos de resignarnos en este ámbito a un estado de naturaleza donde predomine la desconfianza y la posibilidad de agresión? Puesto que no puede haber un pacto entre los débiles y los fuertes, pues estos últimos no tendrían ningún incentivo para el mismo, parece que en las relaciones internacionales nos quedamos con la ley del más fuerte y sin muchas posibilidades de construir una paz estable entre las naciones. Aquí es donde aparecía el comercio como teniendo un papel importante que jugar. Se trataba de una actividad en donde las dos partes participantes podían salir beneficiadas, y eso independientemente de su poder respectivo.

En cuanto a que el valor moral que proporcionaba un criterio para legitimar cualquier práctica era el beneficio de toda la humanidad no podemos sino remitirnos a Montesquieu: "Si yo supiera alguna cosa que me fuera útil, pero que fuera perjudicial para mi familia, la rechazaría de mi mente. Si supiera alguna cosa que fuera útil para mi familia y que no lo fuera para mi patria, trataría de olvidarla. Si supiera alguna cosa que fuera útil para mi patria y que fuera perjudicial para Europa, o bien que fuera útil para Europa y perjudicial para el género humano, la consideraría como un crimen." Igualmente, un segundo texto del mismo autor afirmaba: "Todos los deberes particulares cesan cuando no pueden cumplirse sin 
chocar con los deberes del hombre. ¿Debe pensarse, por ejemplo, en el bien de la Patria, cuando se trata del bien del género humano? No, el deber del ciudadano es un crimen cuando hace olvidar el deber del hombre. La imposibilidad de alinear al universo bajo una misma sociedad ha convertido a los hombres en extranjeros a los hombres, pero ello no ha hecho prescribir los primeros deberes y el hombre, en todas partes razonable, no es ni romano ni bárbaro"22.

Otra cosa es que en el caso de Hume, el pensador que a continuación va a ocupar nuestra atención, sí hubiera "romanos" y "bárbaros". Dicho con más precisión, el problema de Hume es que creía en la inferioridad de la raza negra, luego no está nada claro que sus intereses debieran tenerse en cuanta al mismo nivel que los de otras razas. Hume, en efecto, escribe: "Me inclino por sospechar que los negros son por naturaleza inferiores a los blancos. Apenas ha habido nunca una nación civilizada de ese color de piel, y ni siquiera un individuo eminente en la acción o en la especulación. No existen entre ellos fabricantes ingeniosos, y no cultivan las artes ni las ciencias. Por otra parte, los más rudos y bárbaros de los blancos, como los antiguos germanos o los tártaros actuales, tienen sin embargo algo eminente: su valentía, su forma de gobierno o algún otro particular. Una diferencia tan uniforme y constante no podría darse a la vez en tantos países y épocas si la naturaleza no hubiese establecido una diferencia original entre estas estirpes humanas. Por no mencionar nuestras colonias, hay esclavos negros dispersos por toda Europa, de los que ninguno ha mostrado jamás ningún signo de ingenio, mientras que, entre nosotros, gente baja, sin ninguna educación, llega a distinguirse en todas las profesiones. En Jamaica se habla de un negro que es un hombre de talento. Pero es probable que se le admire por logros menores, como a un loro que llega a pronunciar algunas palabras inteligibles" ${ }^{23}$. ¿Cómo reaccionar ante estas palabras? Lo único que se nos ocurre es que un empirista debiera poder salir fácilmente de los prejuicios que pueda tener. Apelar a la experiencia es aquí la solución. Si hubiera vivido

${ }^{22}$ Ambos textos aparecen citados en Julia Kristeva, Extranjeros para nosotros mismos. Traducción de Xavier Gispert. Barcelona, Plaza y Janés, 1991, pp. 158 y 160 (las referencias que ofrece son Mes pensées, en Oeuvres complètes. La Pléiade, t. I, p. 981; y Analyse du Traité des devoirs. La Pléiade, t. I, p. 110). Las cursivas de la segunda cita son de Julia Kristeva. Podemos contraponer a esta idea de Montesquieu unas declaraciones de Heinrich Himmler que muestran muy bien la inmoralidad a la que el nacionalismo es proclive. En un discurso a líderes de las SS en Polonia en 1943 afirmaba: "Debemos ser honrados, decentes, leales y cordiales con los miembros de nuestra propia sangre y con nadie más. Lo que les ocurra a los rusos, o a los checos, es algo que me deja totalmente indiferente. Debemos apropiarnos de toda la buena sangre como la nuestra que pueda haber en otros países, si es necesario capturando a sus hijos y trayéndolos con nosotros. Si las otras razas viven cómodamente o se mueren de hambre sólo me interesa en la medida en que las necesitemos como esclavas de nuestra cultura. Aparte de tal motivo, no me interesan. Que mueran o no de agotamiento 10.000 mujeres rusas mientras excavan una zanja antitanques sólo me interesa si esa zanja antitanques se excava para Alemania." Citado en Peter Singer, Un solo mundo. La ética de la globalización. Traducción de Francisco Herreros. Barcelona, Paidós, 2003, pp. 166-167.

23 "De los caracteres nacionales", en David Hume, Ensayos morales, políticos y literarios. Edición, prólogo y notas de Eugene F. Miller. Traducción de Carlos Martín Ramírez. Madrid, Ed. Trotta, 2011, p. 204, nota 10. De ahora en adelante citaremos todos los ensayos de Hume por esta edición, ofreciendo primero el título del mismo, luego Ensayos, y por último el número de página. 
unos años más y hubiera tenido ocasión de leer la autobiografía de Olaudah Equiano (un esclavo negro que compró su libertad, y que antes de narrarnos su vida, trabajó en diferentes barcos, llegando incluso a participar en una exploración del Ártico) cabe pensar que hubiera cambiado de opinión.

En todo caso, y volviendo a las palabras de Montesquieu, estas nos desvelan una importante característica del ámbito de nuestras preocupaciones y de la solidaridad humana. La de que cabe esperar que normalmente se ejerzan en círculos concéntricos que van de lo próximo a lo lejano, desde los pequeños grupos a los que uno pertenece, progresando para abarcar al propio país, y llegando a la humanidad en su conjunto. La comparación pertinente aquí sería con una cadena formada por distintos eslabones. Si entendemos esto no debiera haber contradicción entre el hecho de una realidad nacional o supranacional y los ideales éticos universalistas. Lo importante es que quede clara la preeminencia de la humanidad y que el comercio cumplía con esta condición moral. Esto queda muy bien ejemplificado en la teoría de Hume, que ahora pasamos ya a estudiar.

\section{El pensamiento de Hume sobre los resultados del progreso comercial}

No parece que Hume tuviera muchas objeciones morales a participar en una empresa militar que hoy vemos ridícula, y que ya en su tiempo lo fue realmente: una expedición bélica a Canadá que acabó en Francia ${ }^{24}$. Sin embargo, en su pensamiento las cosas son muy distintas ${ }^{25}$. Haciendo un brevísimo resumen de su teoría política hay que decir que para Hume la paz y la seguridad de la sociedad (que es como decir su subsistencia) eran valores extraordinariamente importantes y que dependían de que se respetara la institución de la propiedad privada, aunque, por supuesto quepa discutir qué deba considerarse como propiedad privada de una persona ${ }^{26}$. Es más, si además de que los hombres se soporten los unos a los

${ }^{24}$ Véanse las biografías de Hume, E. C. Mossner, The Life of David Hume, Oxford, Oxford University Press, 1980; y Roderick Graham, The Great Infidel. A Life of David Hume. Edinburgh, Tuckwell Press, 2004.

${ }^{25}$ Como una introducción a la teoría de la sociedad de Hume me permito recomendar mi ensayo titulado "David Hume, liberalismo y cosmopolitismo", algunas de cuyas ideas repetiré aquí. Está publicado en Gerardo López Sastre y Vicente Sanfélix Vidarte, (Eds.), Cosmopolitismo y nacionalismo. De la Ilustración al mundo contemporáneo. Publicaciones de la Universidad de Valencia en Coedición con el Museo Valenciano de la Ilustración y la Modernidad. Valencia, 2010, pp. 85-99. Por otra parte, dos buenas exposiciones del pensamiento político de Hume son Duncan Forbes, Hume's Philosophical Politics, Cambridge, Cambridge University Press, 1975, y David Miller, Philosophy and Ideology in Hume's Political Thought. Oxford, Clarendon Press, 1981.

${ }^{26} \mathrm{Y}$ a este nivel es muy interesante esta reflexión que presenta Hume en uno de sus ensayos: "En la medida de lo posible, toda persona debería disfrutar del fruto de su trabajo, de una plena cobertura de todas sus necesidades y de muchas de las comodidades de la vida. Nadie puede dudar de que esta igualdad es la más apropiada a la naturaleza humana y de que disminuye la felicidad de los ricos en menor medida que aumenta la de los pobres. También aumenta el poder del Estado y hace que se 
otros, queremos que contribuyan al progreso social, se necesita del intercambio por mutuo acuerdo (es decir, del comercio) y de las promesas o contratos, que permiten que ese comercio no sea una mero intercambio en un momento dado, sino que se desplace en el tiempo (tú me das algo hoy y yo te prometo que mañana te entregaré otra cosa). Estas tres instituciones tienen su origen en el egoísmo de las personas, pero -subraya Hume- generan un sistema que "incluyendo el interés de cada individuo, es por supuesto ventajoso para el público, aunque sus inventores no tenían ese propósito"27. Quizás sea aquí, en este pasaje tan parecido al famoso de Adam Smith sobre la mano invisible, donde mejor se muestre el liberalismo de Hume $^{28}$. Un liberalismo que se basa en una consideración atenta de las pasiones de los hombres. La sociedad se mantiene gracias a que nuestra inteligencia enseña (ese sí, a través del lento transcurrir de la Historia) a esas pasiones el camino por el que pueden satisfacerse mejor. Podemos sentirnos extraordinariamente impresionados por el heroísmo y la gloria militar, y ello hasta el punto de que consideremos su búsqueda como el mérito más importante al que podemos aspirar. Pero una reflexión serena sobre la experiencia histórica de sus consecuencias puede llevarnos a tomar conciencia de los numerosos males que las guerras y los enfrentamientos provocan. Cuando ante nuestros ojos (real o imaginativamente) están presentes la devastación de una provincia o el saqueo de una ciudad, escribe Hume, podemos sentirnos más inclinados a odiar

pague más tranquilamente cualquier impuesto o tributo extraordinario. Allí donde son pocos los que se apoderan de la riqueza, tienen que contribuir mucho a la cobertura de las necesidades públicas. En cambio, cuando la riqueza está repartida entre la multitud, la carga sobre los hombros de cada uno resulta más liviana, y los impuestos no ocasionan una diferencia muy sensible en el modo de vida de nadie./ Añádase que, cuando la riqueza está en pocas manos, todo el poder reside en ellas, y sus poseedores no tardarán en conspirar para hacer que toda la carga recaiga sobre los pobres y para oprimirlos más todavía, con lo que se desalienta toda laboriosidad." "Del comercio", Ensayos, p. 250.

${ }^{27}$ David Hume, A Treatise of Human Nature. Edited by L. A. Selby-Bigge, 2nd ed. with text revised by P. H. Nidditch, Oxford, Oxford University Press, 1978, Libro III, Parte II, Sección VI, p. 529. A partir de ahora citaremos por esta edición como Treatise, seguido del libro, parte y sección en números romanos, y luego del número de página.

${ }_{28} \mathrm{Y}$ también lo que el mismo tiene de antiutópico, porque si las instituciones sociales fundamentales no fueron diseñadas por la inteligencia de los hombres con vistas al bienestar del conjunto, sino que surgieron de los paulatinos ajustes del egoísmo de individuos que buscaban su propio beneficio, deberíamos desconfiar de todos los ambiciosos planes de transformación de la sociedad que acarrearían, supuestamente, una realización más plena del bien público (o para lo que a nosotros no interesa ahora, una situación de paz permanente). Véase a este respecto Antony Flew, David Hume. Philosopher of Moral Science, Oxford, Blackwell, 1986, p. 174. Pero esta opinión, aunque puede que represente bastante bien una tendencia del pensamiento de Hume, hay que tomarla con cautela, pues es razonable pensar que en sociedades caracterizadas por un alto nivel de conocimiento y por la difusión social del mismo (como son las actuales) el consenso en torno a las instituciones sociales puede ser el producto de la discusión pública y de la reflexión, y estas tienen capacidad para generar proyectos utópicos. Que Hume no sintiera simpatía por los proyectos que implicaban grandes cambios en el comportamiento de las personas, o no los considerara practicables en su momento, no significa que su teoría los excluyera en otras circunstancias históricas. Al fin y al cabo, él mismo había escrito: "El ser humano es muy variable, y es susceptible de muy distintas opiniones, principios y reglas de conducta. Lo que puede ser verdad mientras se adhiere a un determinado modo de pensar, resultará falso cuando ha adoptado un conjunto de costumbres y opiniones opuesto." "Del comercio", Ensayos, p. 243. 
que a admirar la ambición de los héroes ${ }^{29}$. Aquí vemos cómo un sentimiento es controlado y transformado por otro; y es la razón la que puede muy bien habernos proporcionado la ocasión de experimentar el segundo. La reflexión nos permite percibir las consecuencias nefastas de una acción o de una tendencia que hasta ese momento valorábamos positivamente, y ello sin que cambie la naturaleza humana. Sabemos que el ansia por adquirir bienes y posesiones es insaciable, perpetua y universal. Como observa Hume, la benevolencia hacia los extraños es demasiado débil como para contrapesar su fuerza, y en cuanto a las otras pasiones "más bien inflaman esta avidez, pues observamos que cuanto más grandes son nuestras posesiones más capacidad tenemos para gratificar todos nuestros apetitos" ${ }^{30}$. El afán por poseer, por tanto, actúa en todos nosotros, y todos tenemos motivos para temer su actuación no controlada, pues esta desembocaría en una violencia que nos haría preferir una condición solitaria. Si esto no ocurre es gracias a nuestra sagacidad, a una razón que teniendo en cuenta las enseñanzas de la Historia nos dice que manteniendo la vida social tenemos más posibilidades de adquirir esas posesiones que tanto deseamos y disfrutarlas de manera segura. Este es, por tanto, el sentido, el fundamento, de cualquier nación. Insistamos en ello, se trata de un interés racional: proteger a las personas en cuanto al disfrute de los objetos que poseen, permitirles que los intercambien de tal forma que salgan beneficiados y, por último, que realicen o reciban promesas que saben de manera razonablemente segura que se cumplirán. Y todo esto nos lleva a una pregunta de gran trascendencia. Estas mismas leyes de la justicia que aseguran la vida social, garantizando la paz y promoviendo el progreso, ¿no se aplican igualmente a las relaciones entre las naciones? La respuesta de Hume es matizada. En cierto sentido está claro que sí, porque si toda nación soñara con despojar a los miembros de otras sociedades de sus posesiones (invadiendo el país, etc.) nuestra situación en el ámbito internacional sería de una guerra permanente; si no se contemplara la posibilidad de la transferencia de la propiedad por consentimiento no habría comercio internacional (con lo que los miembros de los diversos países no podrían beneficiarse de los productos de otros climas y suelos o del desarrollo de otras habilidades); $\mathrm{y}$, por último, sin la institución de las promesas no tendrían sentido las alianzas, los tratados, etc., con todo lo que ellos suponen de cooperación y

29 Véase Treatise, III, III, II, pp. 600-601; pero es importante tomar en consideración cómo continúa Hume su reflexión. En cualquier caso, que Hume no tenía idealizada de ninguna manera la vida del soldado y sus supuestas virtudes puede observarse en el siguiente texto: "Las normas de la guerra eran en la Antigüedad mucho más destructivas que en los tiempos modernos, principalmente porque se consentía el saqueo por parte de los soldados. En nuestros ejércitos, los soldados rasos son de una extracción social tan baja que consideramos que cualquier recompensa que vaya más allá de la paga alimenta la confusión y el desorden entre ellos, y una total disolución de la disciplina. La misma condición canalla y mezquina de aquéllos de quienes se nutren los ejércitos modernos hace que sean menos destructivos para los países que invaden. Un ejemplo, más, entre otros muchos, de lo engañoso de las primeras apariencias en el razonamiento político." "De lo populoso de las naciones antiguas", Ensayos, pp. 360-361.

30 Treatise, III, II, II, p. 492. 
apoyo mutuo. Luego es extremadamente ventajoso para todos el que estas leyes se extiendan al ámbito internacional. Como escribe Hume: "las ventajas, por lo tanto, de la paz, el comercio y el socorro mutuo, hacen que extendamos a los diferentes reinos las mismas nociones de justicia que tienen lugar entre los individuos" $"$. El único matiz sobre el que nos previene Hume, es que mientras que del cumplimiento de estas leyes dentro de una sociedad concreta depende la propia existencia de la misma (y por lo tanto de la naturaleza humana, llega a decir), en el caso de las relaciones entre las naciones, por ventajosa que sea una situación de no interferencia mutua (es decir, de paz), de existencia de relaciones comerciales y de cooperación, no está en juego nuestra subsistencia, por lo cual es fácil comprender que las obligaciones a este respecto sean menores ${ }^{32}$.

Si atendemos al conjunto del pensamiento de Hume esto último es muy de lamentar, porque el progreso que cada país obtiene gracias al comercio beneficia también a los demás, algo de lo que estaba tan convencido como para terminar uno de sus ensayos con estas palabras: "No sólo en mi condición de hombre, sino también como súbdito británico, me atrevo en consecuencia a implorar que florezca el comercio de Alemania, España, Italia e incluso Francia. Estoy seguro al menos de que Gran Bretaña y todas esas naciones florecerían mejor si sus soberanos y ministros adoptaran unas posturas mutuas menos estrechas y más benevolentes"33. Aparte de la justificación moral ("en mi condición de hombre"), ¿cuál es la justificación como miembro de una nación? La idea de Hume es que cuando se producen y perfeccionan un gran número de cosas para el mercado interno, siempre se encontrarán algunas que pueden exportarse de forma ventajosa. Pero, ¿cómo podrían comprarlas nuestros vecinos si no tienen nada que ofrecernos a cambio? Luego necesitamos que las otras sociedades sean ricas y prósperas para que puedan consumir el producto de nuestras actividades y nosotros podamos incrementar nuestra riqueza. De esta manera el crecimiento de la industria de un país aumenta el comercio, lo que lleva al crecimiento de la industria de otros países, con lo que aumenta su demanda de bienes, y por lo tanto el progreso de la industria del primer país, y así en un círculo de crecimiento y beneficio mutuo. A este respecto, escribe Hume, "los Estados están en la misma situación que los individuos. Difícilmente podrá ser laboriosa una persona cuyos conciudadanos son ociosos. La riqueza de los distintos miembros de una comunidad contribuye a mi propia riqueza, sea cual fuere la profesión que adopte. Esos otros miembros consumen el producto de mi laboriosidad, y me proporcionan a cambio el producto de la suya"34.

Pero es que además, como también insiste Hume, "Parece existir una feliz concurrencia de causas en los asuntos humanos que controla el

\footnotetext{
${ }^{31}$ Treatise, III, II, XI, pp. 567-568.

${ }_{32}$ Treatise, III, II, XI, p. 569.

33 "De la suspicacia respecto al comercio", Ensayos, p. 303.

${ }^{34}$ Loc. Cit.
} 
crecimiento del comercio y la riqueza y que evita que se limite por entero a un pueblo, como cabría temer en un principio dadas las ventajas de un comercio establecido. Cuando un gobierno ha tomado la delantera a otro en el comercio, le resulta muy difícil al último recuperar el terreno perdido, debido a la superior laboriosidad y destreza en el primer país y a las mayores existencias que poseen sus mercaderes, que les permiten comerciar con márgenes mucho más reducidos. Pero estas ventajas se compensan en alguna medida debido al bajo precio de la mano de obra en los países que no tienen un comercio extenso ni gran abundancia de oro o plata. Los comerciantes van cambiando de plazas, abandonando los países y provincias que ya se han enriquecido y acudiendo a otras atraídos por la baratura de las materias primas y de la mano de obra, hasta que, una vez enriquecidos también éstos, se ven también excluidos por las mismas causas. Y podemos observar, en general, que el encarecimiento de todas las cosas, que provoca la abundancia de dinero, es una desventaja que acompaña al comercio establecido, y le pone límites en todos los países, al permitir a los Estados más pobres vender en todos los mercados a menor precio que los ricos." ${ }^{35}$ Es decir, hay una tendencia natural al equilibrio y a la igualdad entre las naciones, que son así vistas como algo parecido a unos vasos comunicantes.

Y a esto se une, para que esta visión de la dinámica histórica sea todavía más optimista, la observación de que tiene también otro efecto positivo. Donde florecen las industrias y las artes productivas se desarrollan también las artes liberales. Diríamos que el espíritu de la época afecta a todas las artes. La mente, una vez que se despierta de su letargo, se despliega en todas direcciones: Cuanto más avanzan las artes refinadas, "más sociables se hacen las personas, y no es posible que, cuando están enriquecidas con la ciencia y poseen recursos de conversación, se conformen con la soledad, o vivan distantes de sus conciudadanos, a la manera que es propia de las naciones ignorantes y bárbaras. Se agrupan en ciudades; les encanta recibir y comunicar conocimientos, mostrar su ingenio o su educación, sus gustos en la conversación o en el modo de vivir, en el vestido o en los muebles. La curiosidad atrae al sabio; la vanidad, al insensato, y el placer a ambos. Por doquier se forman clubes y sociedades. Los dos sexos se mezclan de una manera relajada y sociable, y el temperamento de las personas, al igual que su comportamiento, se refinan con rapidez. De tal modo que, además de las mejoras que reciben del conocimiento y de las artes liberales, no es posible que dejen de experimentar un aumento de su humanidad, gracias al hábito mismo de conversar con otros y contribuir al mutuo placer y entretenimiento. Así, laboriosidad, conocimiento y humanidad van unidos formando una cadena indisoluble $\mathrm{y}$, tanto la experiencia como la razón consideran que son peculiares de las edades más refinadas, tenidas

\footnotetext{
35 "Del dinero", Ensayos, pp. 265-266.
} 
comúnmente por las de mayor lujo"36.

Tenga o no razón Hume en esta idea de que progreso material y progreso moral van de la mano (y seguramente su percepción era correcta), en lo que acertaba era en percibir las dificultades de aplicar a las relaciones internacionales las leyes de la justicia que había estudiado. Pero, con la perspectiva de la distancia temporal que nos separa del momento histórico en el que Hume desarrollaba su pensamiento, hay que observar que nuestra situación ha cambiado mucho. El descubrimiento de la energía atómica y de su capacidad destructiva, el crecimiento industrial y su efecto sobre el medio ambiente, etc., han ido convirtiendo en cada vez más necesaria esa extensión a las relaciones internacionales de las tres leyes mencionadas. Si Hume observaba que no cumplirlas en el ámbito de una sociedad ponía en peligro a la misma naturaleza humana, ahora encontramos que la situación es la misma en el ámbito de las relaciones entre las naciones en un mundo cada vez más interdependiente. Hume todavía pudo escribir con confianza que "cuando los intereses de un país se interfieren con los de otro estimamos los méritos de un hombre de Estado por el bien o el mal que para su propio país resultan de sus medidas y consejos, sin considerar el perjuicio que ocasione a sus enemigos y rivales. Sus conciudadanos son los objetos que están más cerca de nuestros ojos cuando determinamos su carácter. Y como la naturaleza ha implantado en todos los individuos un mayor afecto por su propio país, nunca esperamos que tengan en cuenta a las naciones lejanas cuando surge un enfrentamiento. Para no mencionar que somos conscientes de que se promueve mejor el interés general de la humanidad cuando cada hombre consulta el bien de su propia comunidad que mediante opiniones indeterminadas e imprecisas sobre el bien de la especie, de las que no podría resultar jamás ninguna acción provechosa por falta de un objeto debidamente limitado sobre el que pudiera emplearse" ${ }^{37}$.

Pues bien, esto ha cambiado completamente. Hoy esta disyuntiva de cómo promover mejor el interés general de la humanidad, si consultando el bien de la propia comunidad o mediante "opiniones indeterminadas" sobre el bien de la especie, nos resulta falsa, porque estamos en condiciones de formar opiniones bien precisas sobre el bien de la especie. Para nosotros, habitantes de una sociedad global en el siglo XXI, todos los habitantes del planeta se han

\footnotetext{
36 "Del refinamiento en las artes", Ensayos, p. 255. La Historia de Inglaterra de Hume es una obra maestra del pensamiento ilustrado precisamente porque ejemplifica en buena medida esta tesis, mostrando el desarrollo de una Inglaterra en la que crecen la libertad, el gobierno moderado, la tolerancia, la extensión del comercio y el desarrollo de las artes y las ciencias. Y en su "De lo populoso de las naciones antiguas" escribía que "Ni el comercio, ni las manufacturas ni la laboriosidad han sido en ningún sitio, en épocas pasadas, tan florecientes como lo son actualmente en Europa." Ensayos, p 369. De lo que cabe inferir que será en Europa donde más se haya desarrollado el sentimiento de humanidad de las personas.

${ }^{37}$ David Hume, Investigación sobre los principios de la moral. Introducción, traducción y notas de Gerardo López Sastre. Madrid, Espasa Calpe, 1991, p. 93, nota a pie de página.
} 
convertido en eso que para Hume faltaba, "un objeto debidamente limitado" al que esperar alcanzar con nuestras acciones.

Luego, concluyendo ya, por la propia lógica del pensamiento de Hume, aplicándolo a nuestra situación, lo que cabría tanto esperar como desear sería el incremento del comercio a escala mundial y una paulatina reducción de las soberanías nacionales a favor de una soberanía mundial, a favor de acuerdos y organizaciones que tomaran en consideración los intereses del conjunto de la humanidad. Al fin y al cabo, esto es lo moral, porque -como insiste Hume una y otra vez- tenemos un sentimiento natural de benevolencia que nos lleva a apreciar y aprobar todo aquello que promueva los intereses de nuestra especie y haga feliz a la sociedad humana ${ }^{38}$. En efecto, nuestra estructura y constitución está dispuesta de tal manera que no nos es indiferente el bienestar de cualquiera de nuestros semejantes. Luego no es sólo nuestro interés a largo plazo el que nos lleva a trascender los límites de las naciones y buscar una convivencia mundial donde podamos sentirnos más seguros y beneficiarnos de intercambios mutuos y de la ayuda que los demás puedan proporcionarnos, es que actuando desde esa perspectiva global manifestamos lo mejor que hay en nosotros. A este respecto, lo verdaderamente importante no es la nación de la que formamos parte, sino esa humanidad a la que pertenecemos. Y Hume comprendió muy bien que el comercio acercaba a las sociedades, hacía que sus costumbres se volvieran más similares, y además incrementaba la humanidad de las personas.

Si Mozi esperaba conseguir la paz a través de la apelación directa a la razón de quienes lo escuchaban o leyeran, si intentaba controlar la historia proponiendo una utopía (algo que cuando se está seguro de contar con una divinidad no parece muy difícil), Hume, más escéptico, intentó comprender la Historia, y creyó haber descubierto que Cromwell tenía razón cuando afirmaba que ningún hombre llega más lejos que aquél que no sabe a dónde se dirige. Los hombres han buscado su beneficio, y por eso, por emplear ejemplos de Hume, han aprendido a fabricar un torno de hilar o a emplear un telar. Pues bien, quienes saben hacer estas cosas es normal que modelen también bien su gobierno, y en ese gobierno se suavizará el temperamento de las personas (pues se volverán mas sociables) y aparecerá de manera más clara el humanitarismo. Quizá una de las tesis más originales de Hume se encuentre en ser capaz de establecer esta relación: "No podemos esperar razonablemente que se produzca una pieza de paño perfecta en un país que ignora la astronomía, o donde se descuida la ética" $"$.

Reflexionando sobre el declive histórico de la violencia en el mundo, Steven Pinker (que debe mucho en este respecto a El proceso de la civilización

${ }^{38}$ Véase David Hume, Investigación sobre los principios de la moral, ed. cit., p. 45; e igualmente las pp. 58, 61, 64, 102-103.

39 "Del refinamiento en las artes", Ensayos, p. 255; y para los ejemplos anteriores véase la página 257. 
de Norbert Elias) habla de cuatro "ángeles" que pueden alejarnos de la violencia y de cinco fuerzas históricas que lo han hecho: nuestros mejores impulsos serían la empatía, el autocontrol, el sentido moral y la capacidad de razonar. Las fuerzas a las que se refiere son el Leviatán (entendido como un Estado que monopoliza el uso legítimo de la fuerza), el comercio, la feminización (es decir, el respeto hacia los intereses y valores de las mujeres), el cosmopolitismo, y por último una redoblada aplicación del conocimiento y la racionalidad a los asuntos humanos ${ }^{40}$. No es difícil ver que en la filosofía de Hume hay un poco de todo esto. Como hemos visto, se insiste en el espíritu de una época en la que las personas prosperan económicamente. A estos individuos les encantará recibir o comunicar sus conocimientos, las relaciones entre los sexos serán más fluidas, los temperamentos mejorarán y el sentimiento de humanidad se incrementará. ¿Cómo de todo esto no iba a surgir la paz? Lo que sí necesitamos es que este proceso no se vea obstruido o paralizado por opiniones falsas (desde la superstición religiosa al mercantilismo), por eso Hume escribió todo lo que aquí hemos visto. Al final, él, como Mozi, confiaba en convencer e iluminar a sus lectores.

${ }^{40}$ Véase Steven Pinker, Los ángeles que llevamos dentro, ed. cit, pp. 24-25. 


\section{Referencias bibliográficas}

Cheng, Anne: Historia del pensamiento chino. Traducción de Anne-Hélêne

Suarez. Bellaterra, Barcelona, 2002.

Flew, Antony: David Hume. Philosopher of Moral Science, Oxford, Blackwell, 1986.

Forbes, Duncan: Hume's Philosophical Politics, Cambridge, Cambridge University Press, 1975.

Freud, Sigmund: El malestar en la cultura y otros ensayos. Traducción de Ramón Rey. Madrid, Alianza Ed., 3 ed., 1975.

Graham, Roderick: The Great Infidel. A Life of David Hume. Edinburgh, Tuckwell Press, 2004.

Hirschman, Albert: Las pasiones y los intereses. Argumentos politicos en favor del capitalismo antes de su triunfo. Prólogo de Amartya Sen y Epílogo de Jeremy Adelman. Traducción de Joan Solé. Madrid, Capitán Swing Libros, 2014.

Holmes, Stephen: Anatomía del antiliberalismo. Trad. de Gonzalo del Puerto. Madrid, Alianza Ed., 1999.

Hume, David: A Treatise of Human Nature. Edited by L. A. Selby-Bigge, 2nd ed. with text revised by P. H. Nidditch, Oxford, Oxford University Press, 1978.

-: Investigación sobre los principios de la moral. Introducción, traducción y notas de Gerardo López Sastre. Madrid, Espasa Calpe, 1991. -: Ensayos morales, políticos y literarios. Edición, prólogo y notas de Eugene F. Miller. Traducción de Carlos Martín Ramírez. Madrid, Ed. Trotta, 2011.

Kristeva, Julia: Extranjeros para nosotros mismos. Traducción de Xavier Gispert. Barcelona, Plaza y Janés, 1991.

López Sastre, Gerardo: "David Hume, liberalismo y cosmopolitismo", en Gerardo López Sastre y Vicente Sanfélix Vidarte, (Eds.), Cosmopolitismo y nacionalismo. De la Ilustración al mundo contemporáneo. Publicaciones de la Universidad de Valencia en Coedición con el Museo Valenciano de la Ilustración y la Modernidad. Valencia, 2010.

Miller, David: Philosophy and Ideology in Hume's Political Thought. Oxford, Clarendon Press, 1981.

Mo Ti, Política del amor universal. Estudio preliminar de Fernando Mateos. Traducción y notas de Carmelo Elorduy. Madrid, Ed. Tecnos, 1987.

Mossner, E. C.: The Life of David Hume, Oxford, Oxford University Press, 1980.

Outram, Dorinda: Panorama de la Ilustración. Traducción de Ramón Martínez Castellote. Barcelona, Blume, 2008.

Paine, Thomas: Derechos del hombre. Traducción, introducción, cronología y notas de Fernando Santos Fontenla. Madrid, Alianza Ed., 1984. 
Pinker, Steven: Los ángeles que llevamos dentro. El declive de la violencia y sus implicaciones. Traducción de Joan Soler Chic. Ed. Paidós, Barcelona, 2012.

Singer, Peter: Un solo mundo. La ética de la globalización. Traducción de Francisco Herreros. Barcelona, Paidós, 2003.

Voltaire: Novelas y cuentos. Introducción, traducción y notas de Carlos Pujol. Barcelona, Ed. Planeta, 1982.

-: Diccionario filosófico. Edición y prólogo de Luis Martínez Drake. Traducción de José Arean Fernández y Luis Martínez Drake. Madrid, Ed. Akal, 2007. 